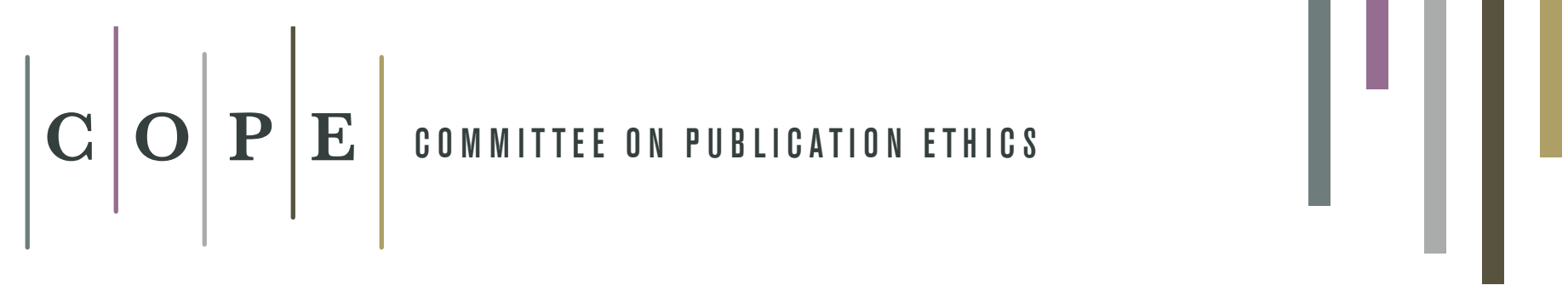

\title{
Changes in authorship
}

\section{(d) Reauest for removal of author after publication}

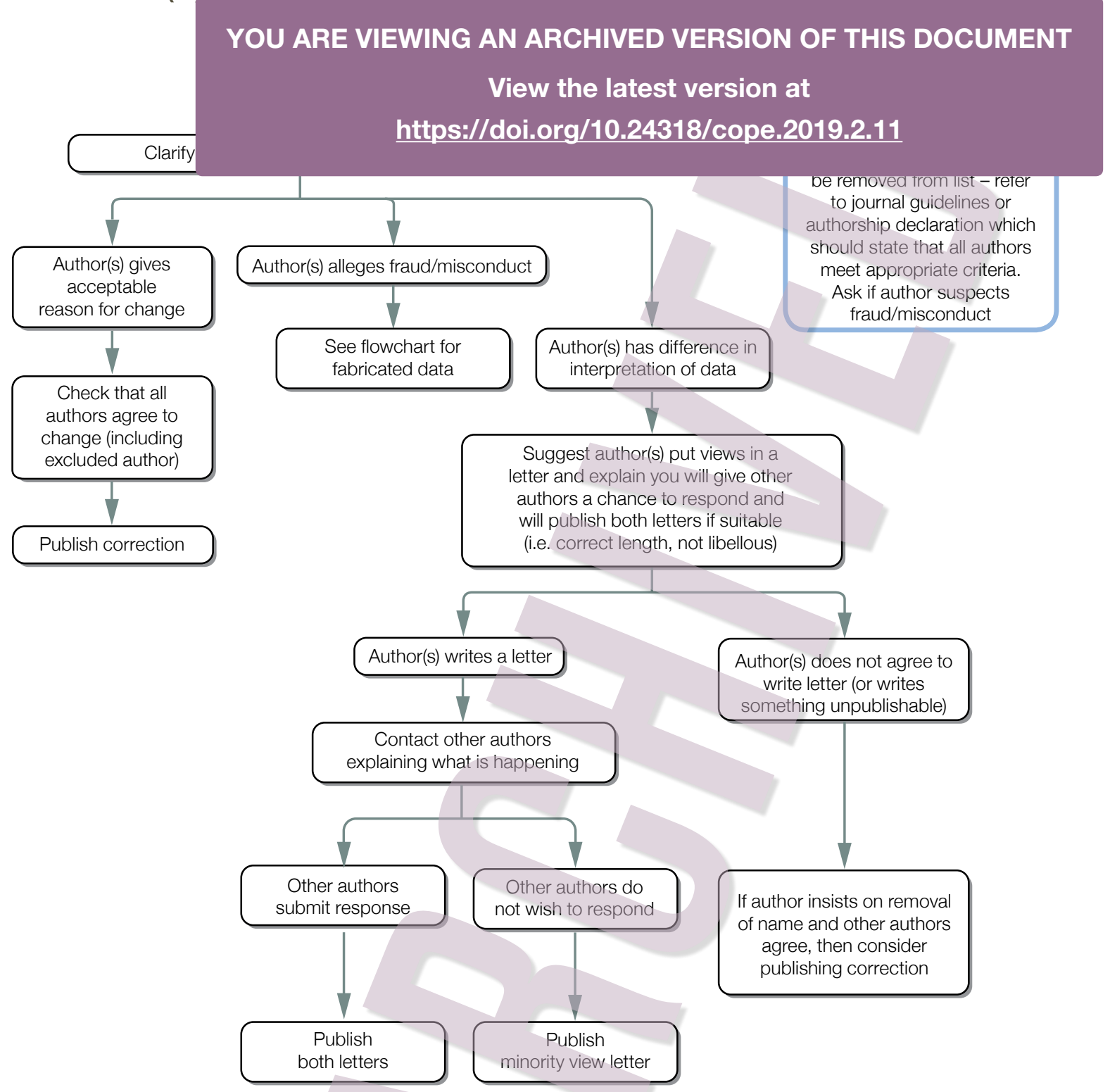

Developed for COPE by Liz Wager of Sideview (www.lizwager.com) (C) 2013 Committee on Publication Ethics First published 2006 